\title{
Correction to: On the morphology of grain boundary discontinuous reactions and phase identification in an advanced $\mathrm{Cr}-\mathrm{Fe}-\mathrm{Ni}$ alloy
}

\author{
J. C. Spadotto ${ }^{1,2, *}$ (D) M. G. Burke ${ }^{2}$, and I. G. Solórzano ${ }^{1}$
}

${ }^{1}$ Department of Chemical and Materials Engineering, PUC-Rio, Rio de Janeiro 22451-900, Brazil

${ }^{2}$ Materials Performance Centre, School of Materials, The University of Manchester, Oxford Road, Manchester M13 9PL, UK

Published online:

11 May 2020

(C) Springer Science+Business

Media, LLC, part of Springer

Nature 2020

Correction to:

J Mater Sci

https://doi.org/10.1007/s10853-020-04690-8

In the original article, Fig. 15 is incorrect. The correct version of the figure is presented below.

The original article can be found online at https:/ / doi.org/10.1007/s10853-020-04690-8.

Address correspondence to E-mail: juliocspadotto@gmail.com 

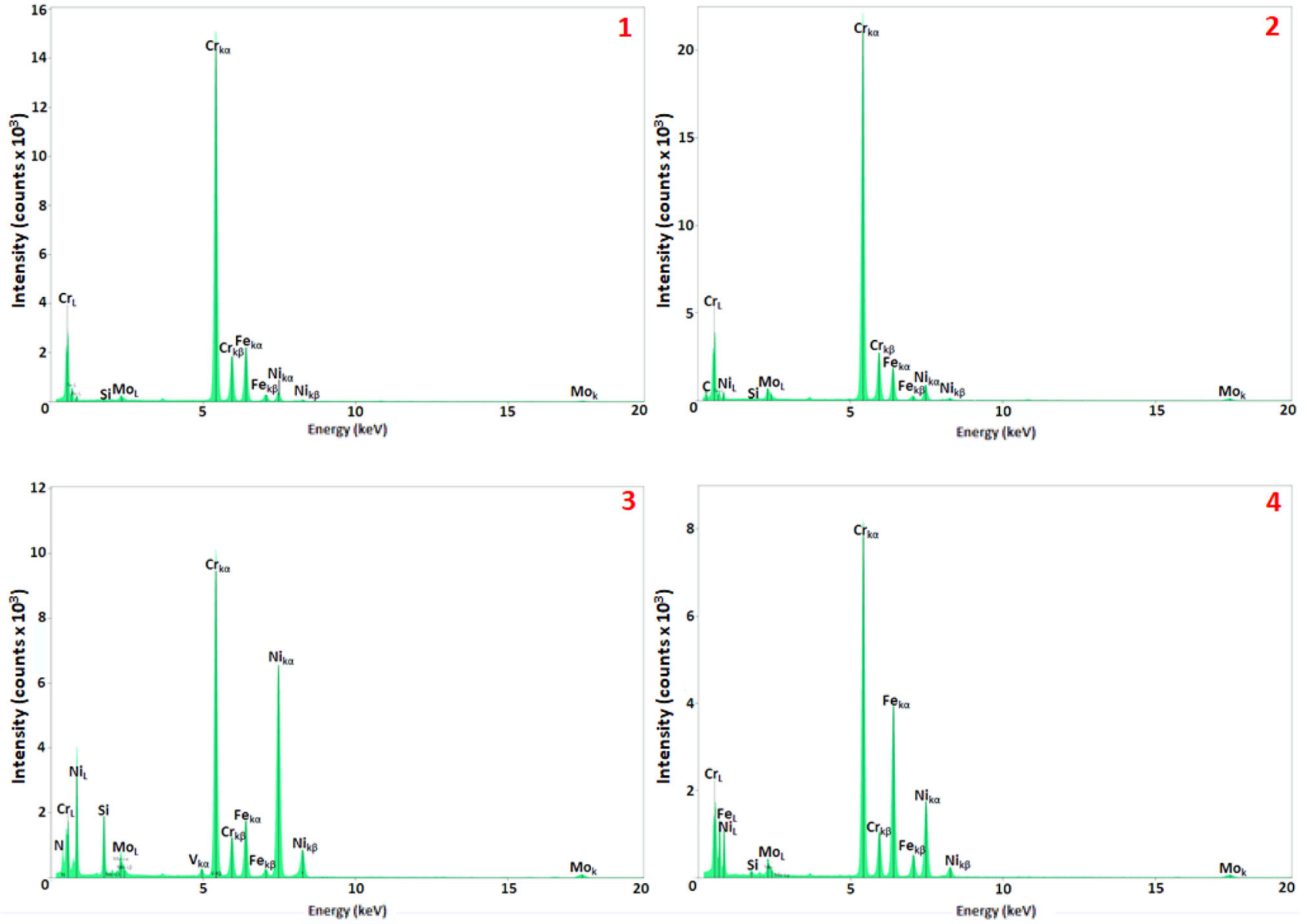

Fig. 15 XED spectra obtained from the precipitates labelled 1, 2, 3, and 4 in Fig. 11. $1 \alpha$-Cr phase $\left(\mathrm{BCC}_{\text {structure }) ; 2} \mathrm{M}_{23} \mathrm{C}_{6}(\mathrm{FCC}\right.$ structure); 3 Si-enriched precipitate; $4 \sigma$-phase (tetragonal structure).

Publisher's Note Springer Nature remains neutral with regard to jurisdictional claims in published maps and institutional affiliations. 